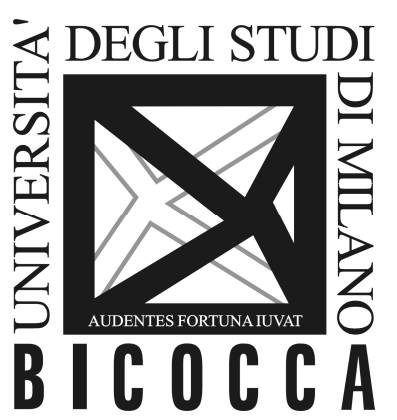

\author{
DEPARTMENT OF ECONOMICS, \\ MANAGEMENT AND STATISTICS \\ UNIVERSITY OF MILAN - BICOCCA
}

DEMS WORKING PAPER SERIES

\title{
Connecting Alone: \\ Smartphone Use, Quality of Social Interactions and Well-being
}

Valentina Rotondi, Luca Stanca, Miriam Tomasuolo

No. 357 - December 2016

Dipartimento di Economia, Metodi Quantitativi e Strategie di Impresa

Università degli Studi di Milano - Bicocca

http://dems.unimib.it/ 


\title{
Connecting Alone: Smartphone Use, Quality of Social Interactions and Well-being
}

\author{
Valentina Rotondi, ${ }^{*}$ Luca Stanca ${ }^{\dagger}$ Miriam Tomasuolo ${ }^{\ddagger}$
}

December 2016

\begin{abstract}
This paper investigates the role played by the smartphone for the quality of social interactions and subjective well-being. We argue that the intrusiveness of the smartphone reduces the quality of face-to-face interactions and their positive impact on well-being. We test this hypothesis in a large and representative sample of Italian individuals. We find that time spent with friends is worth less, in terms of subjective well-being, for individuals who use the smartphone. This finding is robust to the use of alternative empirical specifications or instrumental variables to deal with possible endogeneity. In addition, consistent with the hypothesis that the smartphone undermines the quality of face-to-face interactions, the positive association between time spent with friends and satisfaction with friends is less strong for individuals who use the smartphone.
\end{abstract}

Keywords: Smartphone, Social interactions, Subjective well-being. JEL classification: A12; I31; O33.

${ }^{*}$ Department of Management, Economics and Industrial Engineering (DIG), Politecnico di Milano and University of Milan Bicocca. E-mail: valentina.rotondi@polimi.it

${ }^{\dagger}$ Corresponding author. Department of Economics Management and Statistics, and Neuro-MI, University of Milan-Bicocca, Piazza dell'Ateneo Nuovo 1, 20126, Milan, Italy. E-mail: luca.stanca@unimib.it

${ }^{\ddagger}$ Department of Economics, Catholic University of Milan and University of Milan Bicocca. E-mail: miriam.tomasuolo@unicatt.it 


\section{Introduction}

The advent of the smartphone has changed dramatically the way we access information, allocate time and interact, with relevant implications for behavior, culture and society as a whole. In this paper, we focus on one of these implications: the effect of smartphone use on the quality of face-to-face social interactions. It is widely documented that the quantity and quality of social interactions play a key role for subjective well-being (e.g., Bruni and Stanca, 2008; Bartolini and Bilancini, 2010; Becchetti et al., 2011; Ateca-Amestoy et al., 2014; Capecchi et al., 2016). ${ }^{1}$ We argue that the intrusiveness of the smartphone, arising from its portability and connectivity, reduces the quality of face-to-face social interactions and, as a consequence, their evaluation in terms of satisfaction and well-being.

The first smartphone was marketed in 1993 (Sarwar and Soomro, 2013) and, since then, the smartphone industry has been growing steadily. In 2015, half of the world's population owned a smartphone, for a total of almost two billion individuals. This share is expected to grow and to reach $80 \%$ by 2020 (Economist, 2015). The time spent using the device is also growing. Estimates suggest that people spend on average 5 hours a day on their smartphones (Andrews et al., 2015), with the device being the first thing people look at in the morning, and the last thing they look at before going to sleep. Such impressive figures have made the smartphone by far the world's most popular electronic device.

The smartphone subsumes within a single device a wide range of technologies. It can simultaneously satisfy the need to make a call, take a photo, pay a bill, listen to music, watch a video, use the Internet, chat through social networks and, more generally, be entertained. All these functions have substantially improved and simplified life. However, the very fact that all these activities can be carried out anywhere with ease, has made this technology much more intrusive than any other. While it can be claimed that such ubiquity has improved the way people maintain their interpersonal relationships (Cho, 2015) and fulfill their responsibilities (Derks et al., 2015; Kossek and Lautsch, 2012), anecdotal evidence and experimental studies show that often people ignore those with whom they are physically interacting with, while they prefer to indulge themselves in their smartphones and to connect to "online others" (Turkle, 2012). In the presence of the smartphone, even if it is in silent mode, the need of being constantly connected is strongly perceived. This state of absent-presence (Katz and Aakhus, 2002) diverts attention from face-to-face social interactions. This process, called social fragmentation (Gergen, 2003), comes at the cost of withdrawal from imme-

\footnotetext{
${ }^{1}$ See also the studies that value interpersonal relations by using implicit prices derived from well-being equations (Clark and Oswald, 2002; Powdthavee, 2008; Stanca, 2009) or hedonic prices (Colombo and Stanca, 2014).
} 
diate relationships (Miller-Ott et al., 2012; McDaniel and Coyne, 2016), with a resulting adverse effect in terms of satisfaction with social interactions and, ultimately, well-being.

We test empirically this hypothesis in a large and representative sample of Italian individuals between 2010 and 2014, focusing on time spent with friends as an indicator social interactions. We consider alternative empirical specifications to assess the robustness of the results and implement instrumental variables estimation to deal with the possible endogeneity of time spent with friends and smartphone use. Our findings indicate that time spent with friends is worth less, in terms of well-being, for individuals who use the smartphone. In addition, consistent with the hypothesis that the smartphone undermines the quality of social interactions, we find that the positive association between time spent with friends and satisfaction with friends is less strong for individuals who use the smartphone. Overall, our results are consistent with the hypothesis that the smartphone negatively affects the quality of face-to-face social interactions.

The paper is structured as follows. Section 2 briefly discusses the related literature. Sections 3 and 4 describe the data and methodology, respectively. Section 5 presents the results. Section 6 concludes.

\section{Related literature}

Since the seminal work by Putnam (2000), the literature has devoted much attention to role played by information and communication technologies for social interactions and social capital, with a special focus on television and the Internet. ${ }^{2}$ While some studies find a positive effect of communication technologies on sociability and social relationships (e.g. Bauernschuster et al., 2014; Antoci et al., 2012a), others show that the more time people spend using information technology for virtual interactions, the less time they devote to other social activities and, in particular, face-to-face social interactions (e.g. Mumford and Winner, 2010; Bartolini and Sarracino, 2015). However, different technologies may have different effects on actual social interactions, depending on their degree of intrusiveness. ${ }^{3}$

The literature indicates that many aspects of everyday life can be affected

\footnotetext{
${ }^{2}$ See, e.g., Wellman et al. (2001); Bruni and Stanca (2006); Frey et al. (2007); Bruni and Stanca (2008); Antoci et al. (2012a,b); Stanca et al. (2013); Antoci et al. (2013); Pénard et al. (2013); Antoci et al. (2014, 2015); Misra et al. (2016).

${ }^{3}$ Gergen (2002) proposes a useful contrast between monological presences, such as radio, recording devices, film and television, and dialogic communication technologies, such as telephones, computer games, chats, social networks and the Internet. While technologies in the first category imply a uni-directional communicative flow, without allowing any counter-interaction and are frequently used collectively (e.g., going to the cinema with friends), dialogic communication technologies imply an interactive communication flow and require the instantaneous, although not necessarily physical, connection of the users.
} 
by the use of the smartphone (e.g., Misra and Stokols, 2012; Mumford and Winner, 2010). Several papers have shown that the smartphone can impact on individuals' relational life (e.g. Miller-Ott et al., 2012; McDaniel and Coyne, 2016; Sprecher et al., 2016), that excess use of the smartphone can lead to addiction (e.g. Mok et al., 2014) and reduced capacity to enjoy leisure (Lepp et al., 2015; Janković et al., 2016). At the same time, recent studies have shown that the smartphone has enabled employees to stay connected to their work while away from the office (Derks et al., 2015) and has increased flexibility and workers' ability to combine their work and non-work activities. Furthermore, smartphone-based interventions have been shown to support a wide range of policies, spanning from the adoption of positive health behaviors (Peck et al., 2014) to improving economic development (Aker and Mbiti, 2010) and educational activities (Shin et al., 2011).

The main argument in support of a negative effect of the smartphone in terms of well-being is that the continuous flow of information and communication created by the presence of a smartphone may alter sensory perception. Individuals are constantly exposed to a sensory overload (Misra and Stokols, 2012) that, combined with multitasking possibilities, leads to worsening concentration (Pea et al., 2012), learning (Poldrack and Foerde, 2008) and memorization skills, with a resulting adverse effect in terms of well-being (Lee et al., 2014). Furthermore, the mere presence of a smartphone generates a continuous space where people engage simultaneously in face-to-face and digital relationships and interact without any space or time restrictions (Geser, 2004). This process hinders face-to-face interactions by diverting attention from immediate interpersonal experiences, while making other concerns more salient (Misra et al., 2016).

All these risks are difficult to recognize. Smartphones, tablets and the wi-fi connect people with everybody, everything, always and on the move. This ubiquity witnesses to the development of a new social context where, although connections are growing, people's feeling of isolation is rising.

\section{Data}

Our empirical analysis is based on the Multipurpose Survey on Households (ISTAT, 2015), carried out yearly in Italy since 1993 in a rotating sample of about 24,000 households, corresponding to about 50,000 individuals per year (only 16,832 individual observations are available in 2013). The data set contains detailed information about social behaviors, perceptions and time use in everyday life, in addition to individual- and household-level characteristics. We consider 5 annual waves, from 2010 to 2014, as life satisfaction, the main dependent variable in the analysis, is only available since 2010. Table 1 reports descriptive statistics for the variables used in the empirical analysis.

Subjective well-being is measured with life satisfaction, on a scale between 
Table 1: Summary statistics

\begin{tabular}{lccccc}
\hline \hline \multicolumn{1}{c}{ Variable } & Mean & Std. Dev. & Min. & Max. & N \\
\hline Life satisfaction & 7.05 & 1.70 & 0 & 10 & 144809 \\
Satisfaction with friends & 3.10 & 0.67 & 1 & 4 & 145030 \\
Smartphone use & 0.13 & 0.34 & 0 & 1 & 144830 \\
Time friends & 4.19 & 1.37 & 1 & 6 & 147125 \\
Time friends d1 & 0.70 & 0.46 & 0 & 1 & 147125 \\
Time friends d2 & 0.47 & 0.50 & 0 & 1 & 147125 \\
Male & 0.49 & 0.50 & 0 & 1 & 148088 \\
Age 16-24 & 0.12 & 0.33 & 0 & 1 & 148088 \\
Age 25-34 & 0.15 & 0.36 & 0 & 1 & 148088 \\
Age 35-44 & 0.19 & 0.39 & 0 & 1 & 148088 \\
Age 45-54 & 0.20 & 0.40 & 0 & 1 & 148088 \\
Age 55-64 & 0.19 & 0.39 & 0 & 1 & 148088 \\
Age 65+ & 0.15 & 0.36 & 0 & 1 & 148088 \\
Lower education & 0.48 & 0.50 & 0 & 1 & 148088 \\
Medium education & 0.39 & 0.49 & 0 & 1 & 148088 \\
Upper education & 0.13 & 0.34 & 0 & 1 & 148088 \\
Employed & 0.49 & 0.50 & 0 & 1 & 148088 \\
Unemployed & 0.11 & 0.32 & 0 & 1 & 148088 \\
Married & 0.56 & 0.50 & 0 & 1 & 148088 \\
Divorced & 0.06 & 0.24 & 0 & 1 & 148088 \\
Widowed & 0.04 & 0.20 & 0 & 1 & 148088 \\
Single & 0.32 & 0.47 & 0 & 1 & 148088 \\
Children & 0.49 & 0.50 & 0 & 1 & 148088 \\
Economic cond.: Insufficient & 0.07 & 0.25 & 0 & 1 & 147224 \\
Economic cond.: Poor & 0.38 & 0.48 & 0 & 1 & 147224 \\
Economic cond.: Adequate & 0.54 & 0.5 & 0 & 1 & 147224 \\
Economic cond.: Excellent & 0.01 & 0.10 & 0 & 1 & 147224 \\
Volunteering activity & 0.09 & 0.29 & 0 & 1 & 143830 \\
Attend religious services & 0.80 & 0.40 & 0 & 1 & 144987 \\
Sport activity & 0.32 & 0.47 & 0 & 1 & 147675 \\
4g network (IV) & 0.30 & 0.46 & 0 & 1 & 148088 \\
Avg. time friends (IV) & 0.70 & 0.04 & 0.61 & 0.80 & 148088 \\
2010 & 0.24 & 0.43 & 0 & 1 & 148088 \\
2011 & 0.23 & 0.42 & 0 & 1 & 148088 \\
2012 & 0.23 & 0.42 & 0 & 1 & 148088 \\
2013 & 0.08 & 0.26 & 0 & 1 & 148088 \\
2014 & 0.23 & 0.42 & 0 & 1 & 148088 \\
\hline Source: Multipurpose survey on households & ISTAT & $2015)$ & & &
\end{tabular}


0 and 10. Regarding time spent with friends, we use a variable derived from the following question in the survey: "How often in your free time do you meet with friends?". The variable takes values from 1 to 6 , corresponding to the following categories: never, few times per year, less than 4 times per month, once a week, more than once a week, everyday. For ease of interpretation, we re-code the variable into a binary outcome, taking value 1 when respondents see their friends at least once a week, 0 otherwise (Time friends $d 1$ ). In order to assess the robustness of the results, we also consider an alternative threshold with the resulting dummy equal to 1 when respondents see their friends more than once a week, 0 otherwise (Time friends d2). Smartphone use is measured by a dummy variable equal to one when respondents answer positively to the question: "Do you use your mobile phone to surf the web?", where surfing the web means to make use of the mobile phone to connect to one of the following networks: GPRS, UMTS, 3G, 3G+, WI-FI.

Figure 1 displays the distribution of smartphone penetration and time spent with friends across Italian regions. Over the 5 years under investigation there is substantial variability across regions, with Valle d'Aosta displaying the highest smartphone penetration (21\%) and the lowest fraction of people declaring to see their friends at least once a week (64\%). Figure 1 shows that Italy represents an interesting case study, as the country is characterized by two opposite divides: on the one hand, a North-South digital divide and, on the other hand, a South-North social interactions divide.

Figure 1: Smartphone penetration and time spent with friends, by region
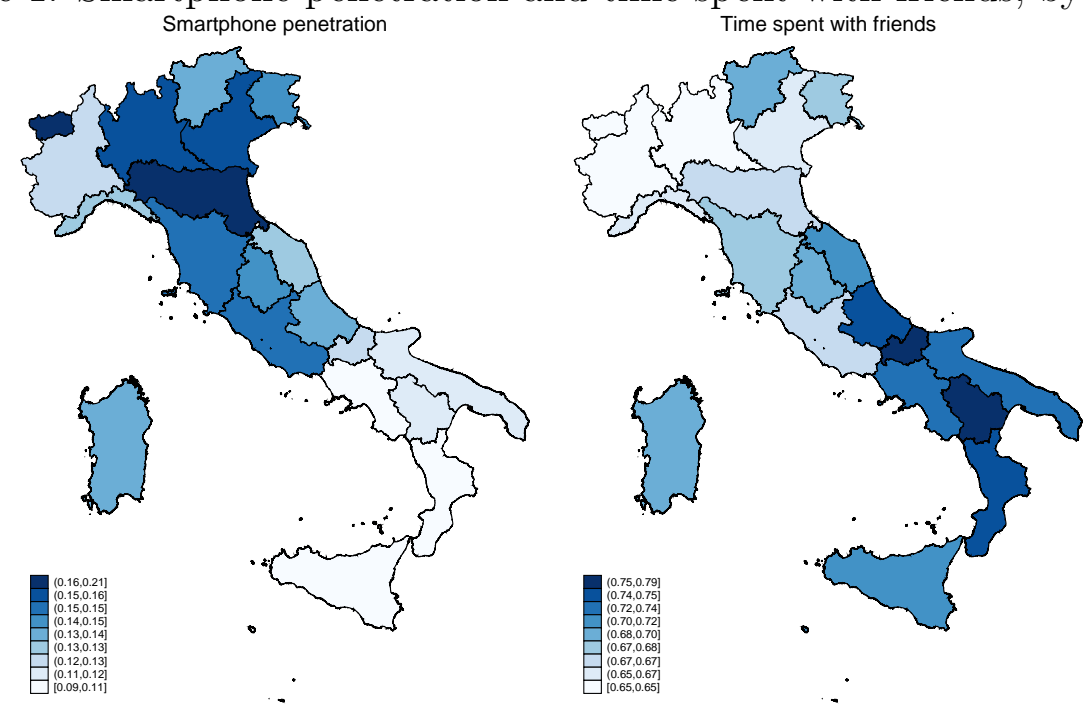

Individual characteristics include age, gender, employment status, marital status, parenthood, educational level, and a self-assessed categorical measure of household's economic conditions (insufficient, poor, adequate, excellent). We also account for participation in volunteering, religious and sport activities. We therefore include, among the regressors, indicators of whether the 
respondent has actively participated in volunteering organizations during the previous 12 months, whether he practices sport or attends church services. We restrict the sample to individuals aged at least 16 years and less than 75 years.

\section{Methods}

Our main hypothesis is that, ceteris paribus, the smartphone negatively affects the quality of face-to-face interactions and, therefore, reduces the positive effect of time spent with friends on well-being. This hypothesis is tested by estimating the following specification:

$$
S W B_{i r t}=\beta_{0}+\beta_{1} T F_{i r t}+\beta_{2} S P_{i r t}+\beta_{3} T F_{i r t} S P_{i r t}+X_{i r t} \Pi+\mu_{r}+\lambda_{t}+\varepsilon_{i r t}
$$

where $S W B$ is the subjective well-being of individual $i$ in region $r$ in year $t$, measured by life satisfaction, $T F$ denotes time spent with friends, $S P$ denotes use of the smartphone, $X_{i r t}$ indicates individual characteristics (described above). Time fixed effects $\left(\lambda_{t}\right)$ are included to allow for heterogeneity between different survey waves. Region dummy variables $\left(\mu_{r}\right)$ are included to control for cultural and societal differences that might play a role in explaining spatial variability in well-being, so that unobserved heterogeneity due to regional-level environmental differences is controlled for. The coefficient $\beta_{3}$ can be interpreted as the difference in the effect of time spent with friends on subjective well-being between smartphone users and non-users. Equation (1) is estimated by OLS, for ease of interpretation, and by Ordered Logit, in order to take into account the ordinal nature of the dependent variable. Standard errors are robust to heteroskedasticity.

An important methodological issue in our analysis is the potential endogeneity of both key explanatory variables, i.e., smartphone use and time spent with friends. There are several possible sources of endogeneity undermining the causal interpretation of the results. First, endogeneity may arise from unobserved heterogeneity at the individual level, as smartphone use, time spent with friends and well-being might be jointly determined by unobserved individual characteristics. It could be the case that, for instance, time spent with friends and smartphone use are simultaneously affected by unobserved personality traits, such as extraversion and low self-esteem (Bianchi and Phillips, 2005). Second, since we make use of pooled cross-sectional data, we cannot rule out reverse causality. It could be the case that happier individuals are more likely to use the smartphone or see their friends more often. In order to address these issues, we make use of instrumental variables estimation (2SLS), considering both time spent with friends and smartphone use as potentially endogenous. We thus obtain a consistent estimator conditional 
on the assumption that the instruments are correlated with the endogenous regressors but not with the error term (i.e., the dependent variable).

\section{Results}

We start by presenting estimation results for our baseline specification, while assessing the robustness of the findings to the use of alternative indicators of social interactions and estimation techniques. Next, we examine the causal interpretation of our results, by addressing the potential endogeneity of both social interactions and the use of the smartphone. Finally, in order to assess the interpretation of the results, we investigate the effects of smartphone use on the evaluation of time spent with friends in terms of satisfaction with friends.

\subsection{Smartphone, Social Interactions and Well-being}

Table 2 presents OLS estimation results for equation (1), based on a sample of about 135,000 individuals. All specifications include region-specific dummies and time-fixed effects. Column (1) reports estimates obtained by using the main dummy variable for time spent with friends. Columns (2) and (3) report, as a robustness check, estimation results obtained by using two alternative definitions of time spent with friends: a dummy variable equal to 1 when respondents see their friends more than once a week (Column 2), or time spent with friends measured on a 6 items scale (Column 3). ${ }^{4}$

We start by considering the results for the control variables, in order to provide a preliminary assessment of the empirical specification. Across individuals, being unemployed is negatively and significantly related to life satisfaction. Individuals who are married, have higher education levels, participate in volunteering activities, practice a sport activity, or attend religious services report significantly higher well-being levels. Males are less satisfied with their life, ceteris paribus, although the effect is only marginally significant. These results, based on the overall sample, are qualitatively consistent with those generally found in the literature.

Time spent with friends is positively and significantly related to wellbeing, consistent with previous findings. Indeed, the main effect is sizable in absolute and relative terms (0.214 and 0.279 , respectively, for the two alternative definitions of dummy variables), being larger than that of volunteering, practicing sport or attending religious services, and slightly smaller (in absolute terms) than that of unemployment status and being married. Smartphone use is positively and significantly related to well-being, with an estimated coefficient in a range between 0.104 and 0.216 across specifications,

\footnotetext{
${ }^{4}$ For space limitations, Table 2 only reports the estimated coefficients for a subset of the explanatory variables (the full set is described in Table 1).
} 
Table 2: Smartphone use, social interactions and well-being (OLS)

\begin{tabular}{|c|c|c|c|}
\hline & $(1)$ & $(2)$ & $\overline{(3)}$ \\
\hline Time friends d1 & $\begin{array}{c}0.279 * * \\
(0.011)\end{array}$ & & \\
\hline Time friends d1 $*$ Smartphone & $\begin{array}{c}-0.122^{* *} \\
(0.030)\end{array}$ & & \\
\hline Time friends d2 & & $\begin{array}{c}0.214^{* *} \\
(0.010)\end{array}$ & \\
\hline Time friends d $2 *$ Smartphone & & $\begin{array}{c}-0.094^{* *} \\
(0.024)\end{array}$ & \\
\hline Time friends & & & $\begin{array}{c}0.118^{* *} \\
(0.004)\end{array}$ \\
\hline Time friends $*$ Smartphone & & & $\begin{array}{c}-0.038 * * \\
(0.011)\end{array}$ \\
\hline Smartphone use & $\begin{array}{c}0.146^{* *} \\
(0.028)\end{array}$ & $\begin{array}{c}0.104^{* *} \\
(0.019)\end{array}$ & $\begin{array}{c}0.216^{* *} \\
(0.050)\end{array}$ \\
\hline Male & $\begin{array}{l}-0.016 \\
(0.009)\end{array}$ & $\begin{array}{l}-0.017 \\
(0.009)\end{array}$ & $\begin{array}{c}-0.030^{* *} \\
(0.009)\end{array}$ \\
\hline Upper education & $\begin{array}{c}0.109 * * \\
(0.014)\end{array}$ & $\begin{array}{c}0.114^{* *} \\
(0.014)\end{array}$ & $\begin{array}{c}0.115^{* *} \\
(0.014)\end{array}$ \\
\hline Medium education & $\begin{array}{c}0.033^{* *} \\
(0.010)\end{array}$ & $\begin{array}{c}0.035 * * \\
(0.010)\end{array}$ & $\begin{array}{c}0.035^{* *} \\
(0.010)\end{array}$ \\
\hline Unemployed & $\begin{array}{c}-0.446^{* *} \\
(0.018)\end{array}$ & $\begin{array}{c}-0.442^{* *} \\
(0.018)\end{array}$ & $\begin{array}{c}-0.447^{* *} \\
(0.018)\end{array}$ \\
\hline Married & $\begin{array}{c}0.381^{* *} \\
(0.014)\end{array}$ & $\begin{array}{c}0.387^{* *} \\
(0.014)\end{array}$ & $\begin{array}{c}0.395^{* *} \\
(0.014)\end{array}$ \\
\hline Volunteering activity & $\begin{array}{c}0.127^{* *} \\
(0.014)\end{array}$ & $\begin{array}{c}0.132^{* *} \\
(0.014)\end{array}$ & $\begin{array}{c}0.118^{* *} \\
(0.014)\end{array}$ \\
\hline Sport activity & $\begin{array}{c}0.197^{* *} \\
(0.010)\end{array}$ & $\begin{array}{c}0.203^{* *} \\
(0.010)\end{array}$ & $\begin{array}{c}0.187^{* *} \\
(0.010)\end{array}$ \\
\hline Attend religious services & $\begin{array}{c}0.252^{* *} \\
(0.012)\end{array}$ & $\begin{array}{c}0.257^{* *} \\
(0.012)\end{array}$ & $\begin{array}{c}0.249^{* *} \\
(0.012)\end{array}$ \\
\hline$R^{2}$ & 0.128 & 0.126 & 0.130 \\
\hline N. & 136882 & 136882 & 136882 \\
\hline
\end{tabular}

Note: Dependent variable: life satisfaction. OLS estimates (heteroskedasticity-robust standard errors in brackets). All specifications include year and region fixed effects and additional explanatory variables (individual characteristics) as described in Table 1. * $\mathrm{p}<0.05,{ }^{* *} \mathrm{p}<0.01$ 
consistent with previous findings in the literature (Cho, 2015). As predicted, the coefficient for the interaction term between smartphone use and time spent with friends is negative (and strongly significant). This indicates that, ceteris paribus, smartphone use partially offsets the positive impact of time spent with friends on well-being. The size of the interaction term, estimated at about $40 \%$ of the main effect for no-smartphone individuals, is also quantitatively relevant.

The negative interaction between smartphone use and time spent with friends is qualitatively and quantitatively robust to the use of alternative indicators of time spent with friends. The coefficient for the interaction term is -0.094 when using the alternative definition of the dummy variable (column 2 ), and -0.038 when using the original discrete variable on a scale between 1 and 6 (columns 3 ). In order to further assess the robustness of the results, Table 3 presents Ordered Logit estimates of equation (1). The results are virtually unchanged.

Table 3: Smartphone, social interactions and well-being (Ordered Logit)

(1) (2) (3)

\begin{tabular}{lc}
\hline Time friends d1 & $0.284^{* *}$ \\
& $(0.012)$ \\
Time friends d1 * Smartphone & $-0.125^{* *}$ \\
& $(0.034)$
\end{tabular}

Time friends $\mathrm{d} 2$

$0.230^{* *}$

Time friends d2* Smartphone $-0.114^{* *}$

$(0.028)$

Time friends

$0.124^{* *}$

Time friends * Smartphone $(0.004)$ $-0.041^{* *}$ $(0.012)$

$\begin{array}{llll}\text { Smartphone use } & 0.157^{* *} & 0.122^{* *} & 0.240^{* *}\end{array}$

\begin{tabular}{lrrr} 
& $(0.031)$ & $(0.022)$ & $(0.056)$ \\
\hline $\mathrm{N}$. & 136882 & 136882 & 136882 \\
\hline Note: Dependent variable: life satisfaction. Ordered Logit estimates (standard errors \\
robust to heteroskedasticity reported in brackets). All specifications include year and \\
region fixed effects and additional explanatory variables (individual characteristics) as \\
described in Table $1 .{ }^{*} \mathrm{p}<0.05,{ }^{* *} \mathrm{p}<0.01$
\end{tabular}

Standard regression analysis provides a simplified picture of the relationship between smartphone use, time spent with friends and subjective 
well-being, since it focuses on the effects of explanatory variable at the mean of the conditional distribution of the dependent variable (Binder and Coad, 2011; Binder, 2015; Yuan and Golpelwar, 2013). However, the moderating role of the smartphone for the effect of time spent with friends on well-being may differ for different levels of well-being. Therefore, we estimate equation (1) by employing quantile regression. ${ }^{5}$

Table 4 presents the results. The negative interaction between smartphone use and time spent with friends becomes smaller (in absolute value), and not statistically significant, as we move towards the upper end of the life satisfaction distribution. For individuals at the bottom of the distribution, the coefficient of the interaction term is larger than the average $(-0.163$ at the $10 \%$ quintile, -0.122 with OLS). At the median life satisfaction, the interaction term is still negative and significant (-0.122), while for individuals at the higher end of the life satisfaction distribution the interaction term is small and not significant (-0.062 and -0.022 for quantiles 0.70 and 0.90 , respectively).

Table 4: Smartphone, social interactions and well-being, quantile regression

\begin{tabular}{lccccc}
\hline \hline & 0.10 & 0.30 & 0.50 & 0.70 & 0.90 \\
\hline Time friends d1 & $0.430^{* *}$ & $0.252^{* *}$ & $0.239^{* *}$ & $0.123^{* *}$ & $0.137^{* *}$ \\
& $(0.021)$ & $(0.011)$ & $(0.012)$ & $(0.007)$ & $(0.020)$ \\
Smartphone use & $0.185^{* *}$ & $0.164^{* *}$ & $0.160^{* *}$ & $0.075^{* *}$ & -0.011 \\
& $(0.058)$ & $(0.030)$ & $(0.029)$ & $(0.013)$ & $(0.043)$ \\
Time friends d1 * Smartphone & $-0.163^{* *}$ & $-0.121^{* *}$ & $-0.122^{* *}$ & -0.062 & -0.022 \\
& $(0.062)$ & $(0.033)$ & $(0.032)$ & $(0.014)$ & $(0.047)$ \\
\hline
\end{tabular}

Note: Quantile regression estimates (heteroskedasticity-robust standard errors in brackets). Number of observations: 136,882. All specifications include year and region fixed effects and additional explanatory variables (individual characteristics) as described in Table 1. ${ }^{*} \mathrm{p}<0.05,{ }^{* *} \mathrm{p}<0.01$

To sum up, time spent with friends has a positive effect on subjective wellbeing. However, this effect is significantly less strong for smartphone users with respect to non-users. The negative interaction between time spent with friends and smartphone use is robust to the use alternative definitions of time spent with friends, and is less strong at the upper end of the distribution of life satisfaction.

\subsection{Endogeneity}

The results presented above provide evidence of a negative interaction between smartphone use and face-to-face relationships. Although we control

\footnotetext{
${ }^{5}$ The distribution of life satisfaction is generally rather skewed (Hohl, 2009; Diener et al., 2006; Binder and Coad, 2011), so that quantile regression may be better suited to represent how the dependent variable responds to changes of the explanatory variable (Hao and Naiman, 2007).
} 
for a large set of individual characteristics, we cannot rule out the possibility that the error term is related to the key explanatory variables. In order to assess the causal interpretation of our results, we thus turn to an instrumental variable (IV) estimator.

It is generally difficult to find appropriate instruments for individuallevel choice variables. We use the variable "introduction of $4 \mathrm{G}$ technology in Italy" $\left(z_{1}\right)$ as an instrument for the use of the smartphone, and the share of respondents in each region/year $\left(z_{2}\right)$ who see their friends at least once a week as an instrument for time spent with friends. Since smartphone use and time spent with friends can be endogenous, their interaction $\left(S_{i r t} R_{i r t}\right)$ will be endogenous as well. Assuming that $z_{1}$ and $z_{2}$ are valid instruments for smartphone use and time spent with friends, respectively, then $z_{3}=z_{1} * z_{2}$ is a valid instrument for their interaction. Therefore, when estimating equation (1), we use $z_{1}$ and $z_{2}$ and their interaction $\left(z_{3}=z_{1} * z_{2}\right)$ as instruments in the reduced form equation.

The introduction of $4 \mathrm{G}$ technology in Italy can be viewed as a natural experiment. $4 \mathrm{G}$, the successor of the $3 \mathrm{G}$ network, is meant to provide ultrabroadband internet access for mobile devices. Italy's incumbent telecommunication company ("Telecom Italia") launched its own $4 \mathrm{G}$ network at the end of 2012 in four cities. Between December 2012 and January 2013, the network has been extended nationwide by "3 Italy "and "Vodafone", the other two telecommunication companies operating in the Italian market together with "Wind", whose 4G was launched in April 2013. Our identifying assumption is that this exogenous change in the network is positively related to smartphone use, while it is exogenous to individual well-being. ${ }^{6}$ Figure 2 displays smartphone penetration (the percentage of respondents who own a smartphone in our sample) interpolated on year, before and after the introduction of the $4 \mathrm{G}$ network. The significant change in smartphone penetration between 2012 and 2013 is consistent with our hypothesis.

As for time spent with friends, we use as an instrument the share of respondents in each region/year who see their friends at least once a week. The rationale behind this instrument is that an individual's relational life is generally easier if she lives in a region where people spend more time with others. We acknowledge that the exogeneity of this instrument could be questioned. For example, it could be the case that richer individuals live in richer regions where smartphones are more common and people enjoy higher (or lower) levels of social interactions. Therefore, in order to control for economic conditions, the set of explanatory variables includes a self-assessed measure of household's economic conditions as a proxy for income and wealth.

\footnotetext{
${ }^{6}$ The $4 \mathrm{G}$ network, in fact, can reach a greater speed during downloads and uploads of files with respect to the pre-existing $3 \mathrm{G}$ network, with a resulting improvement in terms of acceleration of the operations carried out with the smartphone. At the same time, the presence or absence of a $4 \mathrm{G}$ network cannot be influenced by choices made by individuals.
} 
Figure 2: Smartphone penetration before-after the introduction of $4 \mathrm{G}$

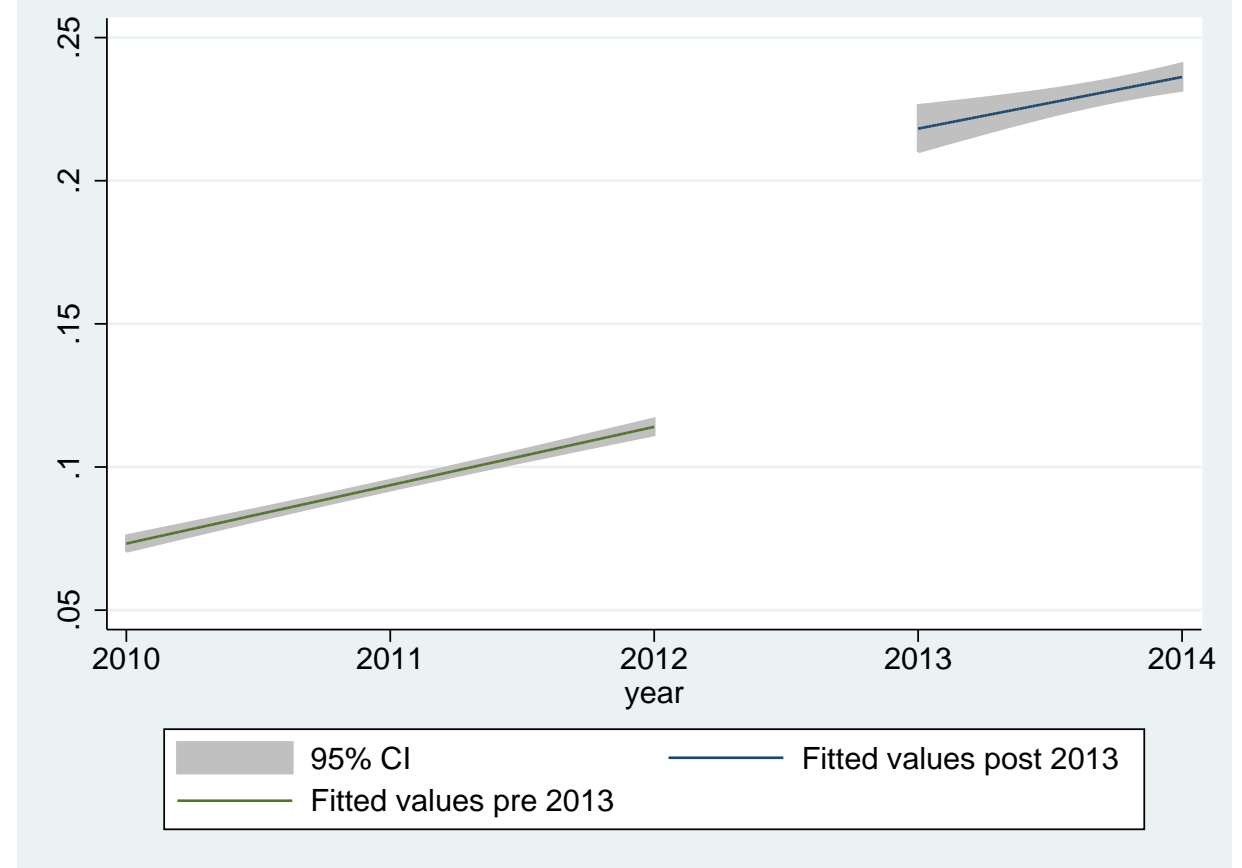

Table 5 reports IV estimation results. First stage results indicate that the instruments are significantly related with the endogenous variables. $F$ tests and Sanderson-Windmeijer multivariate $\mathrm{F}$ test of excluded instruments, a test of weak identification and underidentification, respectively, are reported, together with their significance level, at the bottom of the table for each first stage regression. For the model under investigation, there is no evidence of weak instruments and we can reject the null hypothesis of under-identification at the $1 \%$ significance level. The sign and significance of the interaction term in the second stage results qualitatively confirm the results presented above. The fact that IV estimates are larger than OLS estimates is consistent with attenuation bias caused by measurement error, or may reflect larger standard errors in the presence of weak instruments. Note that the size of the coefficients is not directly comparable across estimation methods, as the OLS model includes region fixed effects while the IV model does not.

\subsection{Smartphone Use and Satisfaction with Friends}

Our proposed interpretation for the negative interaction between time spent with friends and smartphone use in equation (1) is that the smartphone reduces the quality of face-to-face interactions. In order to assess this interpretation, we focus on the moderating role played by the smartphone for the relationship between time spent with friends and satisfaction with friends. Table 6 reports estimation results, based on a specification analogous to 
Table 5: Smartphone, social interactions and well-being, IV estimation

\begin{tabular}{lcccc}
\hline \hline & $(1)$ & $(2)$ & $(3)$ & $(4)$ \\
& Smartphone & Friends & Friends*Smartph. & Life sat. \\
\hline 4g network & $0.115^{* *}$ & 0.025 & 0.032 & \\
& $(0.034)$ & $(0.041)$ & $(0.031)$ & \\
Avg. friends & $-0.327^{* *}$ & $1.052^{* *}$ & $-0.204^{* *}$ & \\
& $(0.021)$ & $(0.033)$ & $(0.020)$ & \\
Avg. friends*4g & 0.009 & -0.030 & $0.102^{*}$ & \\
& $(0.048)$ & $(0.059)$ & $(0.045)$ & $12.794^{* *}$ \\
Smartphone use & & & & $(4.004)$ \\
& & & & 0.865 \\
Time friends d1 & & & & $-17.337^{* *}$ \\
& & & & $(4.740)$ \\
Time friends d1 * Smartphone & & & & \\
& $1438.88^{* *}$ & $426.17^{* *}$ & $1187.94^{* *}$ & \\
\hline F test of excluded instruments & $25.03^{* *}$ & $37.58^{* *}$ & $25.22^{* *}$ & 138008 \\
Sanderson-Windmeijer F test & 139528 & 141533 & 138941 & \\
N. & & & & \\
\hline
\end{tabular}

Note: IV regression (2SLS), heteroskedasticity-robust standard errors in brackets. All specifications include year and region fixed effects and additional explanatory variables (individual characteristics) as described in Table $1 .{ }^{*} \mathrm{p}<0.05,{ }^{* *} \mathrm{p}<0.01$

equation (1). Columns (1) and (2) focus on satisfaction with friends as a dependent variable, using OLS and ordered logit estimation, respectively. Irrespective of the estimation mehtod, the interaction term between smartphone use and time spent with friends is, as above, negative and strongly significant. ${ }^{7}$ This finding indicates that spending time with friends is less valuable, also in terms of satisfaction with friends, for those who use the smartphone, consistent with the hypothesis that the smartphone negatively affects the quality of social interactions.

In order to further asses the effect of smartphone use on relational quality, we construct an indicator of net relational satisfaction, defined as the difference between satisfaction with friends and satisfaction with leisure. ${ }^{8}$ The rationale for using this alternative indicator is that the negative effect of smartphone use on the evaluation of time spent with friends in terms of well-being could be attributed either to a pure fragmentation effect (Lepp et al., 2015; Janković et al., 2016) or, more specifically, to a specific adverse effect on the quality of face-to-face interactions. By taking the difference between satisfaction with friends and satisfaction with leisure we disentangle the adverse relational effect of the smartphone, which includes the increasing overlap between work and family time (Derks et al., 2015, 2016), from

\footnotetext{
${ }^{7}$ Note that the size of the coefficients for well-being and satisfaction with friends are not directly comparable, as the two variables are defined on different scales (0 to 10 and 1 to 4 , respectively).

${ }^{8}$ Satisfaction with friends and satisfaction with leisure are both measured on a four-item scale, with answers ranging from not satisfied at all (1) to very satisfied (4).
} 
Table 6: Smartphone use, time with friends and satisfaction with friends

\begin{tabular}{lccc}
\hline \hline & $(1)$ & $(2)$ & $(3)$ \\
& Sat. friends & Sat. friends & Sat. friends-Sat. leisure \\
\hline Time friends d1 & $0.364^{* *}$ & $1.123^{* *}$ & $0.093^{* *}$ \\
& $(0.004)$ & $(0.015)$ & $(0.005)$ \\
Smartphone & $0.078^{* *}$ & $0.219^{* *}$ & $0.065^{* *}$ \\
& $(0.012)$ & $(0.040)$ & $(0.015)$ \\
Time friends d1 * Smartphone & $-0.060^{* *}$ & $-0.141^{* *}$ & $-0.050^{* *}$ \\
& $(0.013)$ & $(0.044)$ & $(0.017)$ \\
\hline N. & 137205 & 137205 & 136998
\end{tabular}

Note: OLS estimates (heteroskedasticity-robust standard errors in brackets). All specifications include year and region fixed effects and additional explanatory variables (individual characteristics) as described in Table $1 .{ }^{*} \mathrm{p}<0.05,{ }^{* *} \mathrm{p}<0.01$

the more general fragmentation effect on time use (Lepp et al., 2015). The results, reported in column (3), indicate that the interaction between time spent with friends and smartphone use is negative, statistically significant, and quantitatively relevant. This suggests that the adverse effect of the smartphone on the quality of face-to-face interactions is present even when controlling for the fragmentation effect. This provides further support to the interpretation focusing on the adverse effect of the smartphone on the quality of face-to-face interactions.

\section{Concluding remarks}

About 20 years ago the smartphone has appeared in our daily lives. Since then, it has dramatically changed how we do things and interact with other people. These changes have simplified our lives in many respects. Yet, they did not come without costs. This paper attempted to shed light on one of these potential costs, the adverse effect of smartphone use on the quality of social interactions. We argued that the intrusiveness of the smartphone, arising from its powerful connecting capabilities together with small size and portability, reduces the quality of face-to-face social interactions, thus dampening their positive impact on well-being.

We tested this hypothesis empirically in a large and representative sample of Italian individuals. Our results suggest that the use of the smartphone negatively affects the quality of time spent with friends, with an effect that decreases monotonically along the distribution of well-being. This finding is robust to the use of alternative specifications and estimation techniques to deal with possible endogeneity. Consistent with our hypothesis, we also find that the positive association between time spent with friends and satisfaction with friends is less strong for individuals who use the smartphone.

Our results have important policy implications. The smartphone is by far the the world's most popular and intrusive electronic device. Its functions 
permeate daily life to such an extent that, according to the latest available Pew Research Center data, $46 \%$ of smartphone owners say they could not live without their phone (Smith et al., 2015). Seminal technologies require people to adapt to them and smartphones are no exception. This process of adaptation, however, requires careful attention and a better understanding of the mechanisms through which such major changes occur in our daily life.

Smartphones can be empowering in many respects. They reduce the cost of information gathering, enable individuals to work from anywhere they wish, can help spread important information that can favor disadvantaged groups. However, all these positive aspects come with important costs. While the smartphone can bring distant people closer together, at least virtually, it can also make close people more distant. More generally, it can negatively affect the quality of time spent with ohers, which is a major determinant of individual well-being. This relational cost can be expected to become more relevant as smartphones become more widespread, more intrusive and smarter than ever. One of the goals of social scientists is to understand how homo smartphoniens can adapt to this new technology without letting it take away what makes us human: the relationships with other humans. 


\section{References}

Aker, J. C. and Mbiti, I. M. (2010). Mobile phones and economic development in africa. The Journal of Economic Perspectives, 24(3):207-232.

Andrews, S., Ellis, D. A., Shaw, H., and Piwek, L. (2015). Beyond selfreport: Tools to compare estimated and real-world smartphone use. PloS one, 10(10):e0139004.

Antoci, A., Sabatini, F., and Sodini, M. (2012a). See you on facebook! a framework for analyzing the role of computer-mediated interaction in the evolution of social capital. The Journal of Socio-Economics, 41(5):541547.

Antoci, A., Sabatini, F., and Sodini, M. (2012b). The solaria syndrome: Social capital in a growing hyper-technological economy. Journal of Economic Behavior \&f Organization, 81(3):802-814.

Antoci, A., Sabatini, F., and Sodini, M. (2013). Economic growth, technological progress and social capital: the inverted u hypothesis. Metroeconomica, 64(3):401-431.

Antoci, A., Sabatini, F., and Sodini, M. (2014). Bowling alone but tweeting together: the evolution of human interaction in the social networking era. Quality \& Quantity, 48(4):1911-1927.

Antoci, A., Sabatini, F., and Sodini, M. (2015). Online and offline social participation and social poverty traps: Can social networks save human relations? The Journal of Mathematical Sociology, 39(4):229-256.

Ateca-Amestoy, V., Aguilar, A. C., and Moro-Egido, A. I. (2014). Social interactions and life satisfaction: Evidence from latin america. Journal of Happiness Studies, 15(3):527-554.

Bartolini, S. and Bilancini, E. (2010). If not only gdp, what else? using relational goods to predict the trends of subjective well-being. International Review of Economics, 57(2):199-213.

Bartolini, S. and Sarracino, F. (2015). The dark side of Chinese growth: Declining social capital and well-being in times of economic boom. World Development, 74:333-351.

Bauernschuster, S., Falck, O., and Woessmann, L. (2014). Surfing alone? the internet and social capital: Evidence from an unforeseeable technological mistake. Journal of Public Economics, 117:73-89.

Becchetti, L., Trovato, G., and Londono Bedoya, D. A. (2011). Income, relational goods and happiness. Applied Economics, 43(3):273-290. 
Bianchi, A. and Phillips, J. G. (2005). Psychological predictors of problem mobile phone use. CyberPsychology \& Behavior, 8(1):39-51.

Binder, M. (2015). Volunteering and life satisfaction: a closer look at the hypothesis that volunteering more strongly benefits the unhappy. Applied Economics Letters, 22(11):874-885.

Binder, M. and Coad, A. (2011). From average joe's happiness to miserable jane and cheerful john: using quantile regressions to analyze the full subjective well-being distribution. Journal of Economic Behavior $\&$ Organization, 79(3):275-290.

Bruni, L. and Stanca, L. (2006). Income aspirations, television and happiness: Evidence from the world values survey. Kyklos, 59(2):209-225.

Bruni, L. and Stanca, L. (2008). Watching alone: Relational goods, television and happiness. Journal of Economic Behavior \& Organization, 65(3):506528.

Capechi, S., Iannario, M., and Simone, R. (2016). Well-being and relational goods: A model-based approach to detect significant relationships. Social Indicators Research, pages 1-22.

Cho, J. (2015). Roles of smartphone app use in improving social capital and reducing social isolation. Cyberpsychology, Behavior, and Social Networking, 18(6):350-355.

Clark, A. E. and Oswald, A. J. (2002). A simple statistical method for measuring how life events affect happiness. International Journal of Epidemiology, 31(6):1139-1144.

Colombo, E. and Stanca, L. (2014). Measuring the monetary value of social relations: a hedonic approach. Journal of Behavioral and Experimental Economics, 50:77-87.

Derks, D., Bakker, A. B., Peters, P., and van Wingerden, P. (2016). Workrelated smartphone use, work-family conflict and family role performance: The role of segmentation preference. human relations, 69(5):1045-1068.

Derks, D., Duin, D., Tims, M., and Bakker, A. B. (2015). Smartphone use and work-home interference: The moderating role of social norms and employee work engagement. Journal of Occupational and Organizational Psychology, 88(1):155-177.

Diener, E., Lucas, R. E., and Scollon, C. N. (2006). Beyond the hedonic treadmill: revising the adaptation theory of well-being. American psychologist, 61(4):305. 
Economist (Feb 28th 2015). Planet of the phones. The Economist.

Frey, B. S., Benesch, C., and Stutzer, A. (2007). Does watching tv make us happy? Journal of Economic psychology, 28(3):283-313.

Gergen, K. J. (2002). Cell phone technology and the challenge of absent presence. Department of Psychology, Swarthmore College.

Gergen, K. J. (2003). Self and community in the new floating worlds.

Geser, H. (2004). Towards a sociological theory of the mobile phone. EMerging media: communication and the media economy of the future, pages $235-260$.

Hao, L. and Naiman, D. Q. (2007). Quantile regression. Number 149. Sage.

Hohl, K. (2009). Beyond the average case: The mean focus fallacy of standard linear regression and the use of quantile regression for the social sciences. SSRN Working Paper Series.

ISTAT (2015). Multipurpose survey on households: aspects of daily life. Technical report, Italian National Institute of Statistics, http://www.istat.it/it/archivio/91926.

Janković, B., Nikolić, M., Vukonjanski, J., and Terek, E. (2016). The impact of facebook and smart phone usage on the leisure activities and college adjustment of students in serbia. Computers in Human Behavior, 55:354363.

Katz, J. E. and Aakhus, M. (2002). Perpetual contact: Mobile communication, private talk, public performance. Cambridge University Press.

Kossek, E. E. and Lautsch, B. A. (2012). Work-family boundary management styles in organizations a cross-level model. Organizational Psychology Review, 2(2):152-171.

Lee, Y.-K., Chang, C.-T., Lin, Y., and Cheng, Z.-H. (2014). The dark side of smartphone usage: Psychological traits, compulsive behavior and technostress. Computers in Human Behavior, 31:373-383.

Lepp, A., Li, J., Barkley, J. E., and Salehi-Esfahani, S. (2015). Exploring the relationships between college students cell phone use, personality and leisure. Computers in Human Behavior, 43:210-219.

McDaniel, B. T. and Coyne, S. M. (2016). Technoference: The interference of technology in couple relationships and implications for womens personal and relational well-being. Psychology of Popular Media Culture, 5(1):85. 
Miller-Ott, A. E., Kelly, L., and Duran, R. L. (2012). The effects of cell phone usage rules on satisfaction in romantic relationships. Communication Quarterly, 60(1):17-34.

Misra, S., Cheng, L., Genevie, J., and Yuan, M. (2016). The iphone effect the quality of in-person social interactions in the presence of mobile devices. Environment and Behavior, 48(2):275-298.

Misra, S. and Stokols, D. (2012). A typology of people-environment relationships in the digital age. Technology in Society, 34(4):311-325.

Mok, J.-Y., Choi, S.-W., Kim, D.-J., Choi, J.-S., Lee, J., Ahn, H., Choi, E.-J., and Song, W.-Y. (2014). Latent class analysis on internet and smartphone addiction in college students. Neuropsychiatric disease and treatment, 10:817.

Mumford, L. and Winner, L. (2010). Technics and civilization. University of Chicago Press.

Pea, R., Nass, C., Meheula, L., Rance, M., Kumar, A., Bamford, H., Nass, M., Simha, A., Stillerman, B., Yang, S., et al. (2012). Media use, faceto-face communication, media multitasking, and social well-being among 8-to 12-year-old girls. Developmental psychology, 48(2):327.

Peck, J. L., Stanton, M., and Reynolds, G. E. (2014). Smartphone preventive health care: Parental use of an immunization reminder system. Journal of Pediatric Health Care, 28(1):35-42.

Pénard, T., Poussing, N., and Suire, R. (2013). Does the internet make people happier? The Journal of Socio-Economics, 46:105-116.

Poldrack, R. A. and Foerde, K. (2008). Category learning and the memory systems debate. Neuroscience $\& 5$ Biobehavioral Reviews, 32(2):197-205.

Powdthavee, N. (2008). Putting a price tag on friends, relatives, and neighbours: Using surveys of life satisfaction to value social relationships. The Journal of Socio-Economics, 37(4):1459-1480.

Putnam, R. D. (2000). Bowling alone: The collapse and revival of American democracy. Simon and Schuster Nova York.

Sarwar, M. and Soomro, T. R. (2013). Impact of smartphones on society. European Journal of Scientific Research, 98(2):216-226.

Shin, D.-H., Shin, Y.-J., Choo, H., and Beom, K. (2011). Smartphones as smart pedagogical tools: Implications for smartphones as u-learning devices. Computers in Human Behavior, 27(6):2207-2214. 
Smith, A., McGeeney, K., Duggan, M., Rainie, L., and Keeter, S. (2015). U.s. smartphone use in 2015. Technical report, Pew Research Center.

Sprecher, S., Hampton, A. J., Heinzel, H. J., and Felmlee, D. (2016). Can I connect with both you and my social network? access to network-salient communication technology and get-acquainted interactions. Computers in Human Behavior, 62:423-432.

Stanca, L. (2009). With or without you? measuring the quality of relational life throughout the world. The Journal of socio-economics, 38(5):834-842.

Stanca, L., Gui, M., and Gallucci, M. (2013). Attracted but unsatisfied: The effects of sensational content on television consumption choices. Journal of Media Economics, 26(2):82-97.

Turkle, S. (2012). Alone together: Why we expect more from technology and less from each other. Basic books.

Wellman, B., Haase, A. Q., Witte, J., and Hampton, K. (2001). Does the internet increase, decrease, or supplement social capital? social networks, participation, and community commitment. American behavioral scientist, 45(3):436-455.

Yuan, H. and Golpelwar, M. (2013). Testing subjective well-being from the perspective of social quality: Quantile regression evidence from shanghai, china. Social indicators research, 113(1):257-276. 